Калинина Г.Н.

\title{
Философско-культурологическое определение паранауки в контексте специфики паранаучного дискурса
}

Аннотация: Объектом исследования является феномен парануки. Предметом выступает паранаука как культурно-исторический феномен и субкультура. Автор подробно рассматривает такие аспекты, как: исследование взаимоотношения науки и паранауки в культурно-исторической динамике и современном культурном контексте. Вырабатывается собственное философско-культурологическое определение паранауки как субкультуры, эволюционирующей от маргинальности к антисистемности. Особое внимание уделяется аспекту авторского обоснования сущностной специфики паранаучных деструктивных форм, мимикрирующцх «под науку» и основным характеристикам паранаучного субкультурного комплекса. В исследовании культурно-исторической феноменологии паранауки автор опирается на мультидисциплинарный подход и философско-методологическое понимание сущности культуры с учетом хронотопных характеристик деятельного, конкретно-исторического индивида, включенного в специфические субкультурные сообщества и группы. Основным методом работы послужил классический метод диалектики. Новизна исследования философско-теоретической проблемы культурно-исторической феноменологии паранауки обусловлена, прежде всего, ее решением на пересечении классических и неклассических методологических парадигм познания в онтологических и эпистемологических основаниях и состоит в философско-культурологическом понимании паранауки как субкультурного формообразования в различных культурно-исторических системах знания. Основной вывод по данной статье: предложено философско-культурологчческое определение паранауки как субкультуры в контексте специфики паранаучного дискурса.

Ключевые слова: Паранаучный субкультурный комплекс, мимикрия, деструктивные формообразования, паранаучный дискурс, рационализм, наука, субкультура, культура, пограничность, маргинальность.

Review: The object of the research is the phenomenon of parascience. The subject of the research is parascience as a cultural and historical phenomenon and subculture. The author of the article examines such aspects of the topic as the relationship between science and parascience from the point of view of their cultural and historical development as well as modern environment. The author also develops her own philosophical and cultural definition of parascience as a subculture that has evolved from marginality to antisystematicity. Special attention is paid to the aspect of the author's substantiation of essential features of parascientific destructive forms that try to look like science as well as the main characteristics of the parascientific subcultural complex. The author of the research bases her research of the cultural and historical phenomenology of parascience on the multi-disciplinary approach and philosophical-methodological concepts of culture taking into account chronotopos characteristics of an active concrete-historical individual involved in specific subcultural communities and groups. The main research method used by the author is a classical dialectical method. The novelty of the research is caused by the fact that the author focuses on the philosophical and theoretical problem of cultural and historical phenomenology of parascience because, first of all, solution of this problem can be found at the intersection of classical and non-classical methodological paradigms of knowledge based on ontological and epistemological grounds. According to the author, in order to solve the problem it is necessary to establish a philosophical and cultural concept of parascience as a subcultural formation in different cultural and historical knowledge systems. As the main conclusion of the research, the author offers her own philosophical and culturological definition of parascience as a subculture in terms of specifics of the parascientific discourse.

Keywords: Marginality, borderline, parascientific subculture complex, mimicry, destructive formations, parascientific discourse, rationalism, science, subculture, culture. 
$\mathrm{B}$ рамках проблемного поля данной статьи необходимо оговориться, что мы придерживаемся корректного методологического использования понятия «субкультура», означающего, что любая система культуры или культурная система предполагает субсистемную стратификацию, наличие субструктур и субэлементов, а, тем самым, и наличие субкультур.

Вполне очевидно: сегодня сфера духовного производства характеризуется плюралистичностью и расширением познавательного пространства. Однако в условиях недостаточного уровня общей культуры и культуры знания в частности, эти процессы служат питательной средой для генерации, активизации и популяризации паранауки. существенную часть которой составляют так называемые «новые научные теории и представления». Надо сказать, что паранаучное знание (оно же, как отмечается в источниках, и форма вненаучного знания) понимается достаточно широко. Скажем, и как «несовместимое с имеющимся гносеологическим стандартом, включающее в себя учения о феноменах, объяснение которых не является убедительным с точки зрения критериев научности» [1, с.12]; и как "многообразие идейно-теоретических концепций, течений, представлений, связанных с наукой общностью проблематики и методологии, наукообразных по форме, но ненаучных по сути»; и как проведение сомнительных или заведомо ложных исследований и наблюдений» [2, с. 34-35] . К категории паранаучного знания нередко причисляются и «ложные религиозные направления (оккультизм, эзотеризм. Достаточно широко представлен в источниках и так называемый психологический портрет (он же «собирательный образ») параученого. В большинстве своем, паранаучный комплекс трактуется в категориях «маргинального», «периферийного» по отношению к науке знания. Это же верно в отношении паранаучных коммуникаций и ученых-индивидуалов).

Представляется, что на общем фоне описания паранаучного феномена, полнотой анализа отличаются исследования С.П. Щавелева, который дает определение паранауки, выполненное с научно-философских позиций, «... перед нами своего рода модернизированная мифология, то есть иллюзорные формы человеческого сознания, обслуживающие тем не менее некие реалии и потребности личности и социума; Яркий образец «мутирова- ния» внешней атрибутики науки - индустрия присуждения уже не просто общественных, а прямо поддельных «наград» некоторым представителем паранауки» [3, с. 160-161]. В ряду отличительных черт паранауки назовем такие как: сопротивление и игнорирование результатов независимой экспериментальной проверки; аллергия на критику; мечта о невозможном; агрессивная реклама реалистичности и эффективности; конкуренция с легитимными способами познания и практики; тотальность претензий на истину, пользу; сенсационность заявок на «открытия» «изобретения». Строго говоря, паранаука выступает специфической промежуточной (можно сказать «пограничной») субкультурной подсистемой на границах науки, отражая неоднородность содержания самой науки.

Если же говорить о генеалогии данного культурного и психологического феномена (паранаука), то он включает в себя широко известные в истории культуры духовно-практические проекты (первобытная мифология, мантика, медицинский оккультизм, алхимия, астрология, спиритизм, теософия, религиозные секты с претензией на теоретическое обоснование своих доктрин [3, с. 164-165] . Примечательно, что свое особое место в данном ряду занимает культурно-истоиический феномен масонства. Так, на фоне всеобщего торжества науки масонство стало как бы неким фантомом обыденного сознания, к которому подчас прибегают для истолкования не только событий прошлого, но и некоторых явлений настоящего. Интерес к масонству является частью социальной психологии нашего общества, обретшей после долгой полосы запретов тягу, не редко чрезмерную, ко всему таинственному, лежащему за рамками традиционного рационалистического мировидения [4, с. 8]. Возможно, подобное влечение есть выражение вполне искреннего стремления доискаться источников перводвижений человеческого духа.

По нашему мнению, субкультурность паранауки связана, по меньшей мере, с тремя основными моментами: 1) распространение научного мышления (образцов рационального знания) на области духовного опыта личности; 2) создание образцов паранауки, начиная со средних веков и Возрождения (алхимия, астрология, магия); 3) формирование сообщества параученых, включая рефлексию их творчества и пропаганду видения мира. Поэтому бессмысленно её отрицать - 
это реальный культурно-психологический феномен, своего рода плата за возможность бытия разумной личности и научной рациональности [5, с. 11]. Требуется понять ее природу, связь с наукой, основные функции и неоднозначную «миссию в обществе». Особой рефлексии требуют негативные социокультурные последствия паранаучного маргинального дискурса. В то же время своей критической оценки требует огульное отрицание паранаучных поисков и квалификация их как антинаучных. Примечательно, что, на сегодняшнем поле нетрадиционно ориентированных мыслительных стратегий серьезно осмысливается проблема возможности науки о сакральном мире. Так, по мнению В.M. Розина, учение шведского мистика Э. Сведенборга, изложенное в книге «О небесах, о мире духов и об аде», может пониматься не просто как откровение, но и как научное познание духовного мира - оно сознательно выстроено как духовная наука [6, 7].

Неоднородность и тенденциознось трактовок феномена паранауки, характерная для основного массива источников, в которых представлены ее дифиниции, подводят к необходимости выработки собственного философско-методологического понимания этого специфического культурного и психологического феномена, функционирующего на границах науки.

Идентификакция субкультурности паранауки как подсистемы целостной системы культуры, выявление ее специфики и характеристик в рамках системного самоопределения позволяют нам придти к выводу о том, что паранаука представляет собой специицческий субкультурныцй комплекс маргинальных Форм знания и практик, который характеризуется размывчатостью рациональной составляющей; наличием вне- и иррациональных копмонентов, выходящих за рамки рефлективного анализа; паранаука апеллирует в условиях потери наукой единых методологических ориентиров к факту условности и плюрализма научных норм; претендует на научный статус, эксплуатируя традиционный авторитет науки в целях фиктивного решения социально-гуманитарных проблем и реализации социокультурных технологий. Наше определение предполагает компенсацию некоторых (выявленных в источниках) ограниченных (или же не вполне корректных) интерпретаций паранауки как понятия и феномена. Этому мы стараемся следовать, выделяя паранаучную форму из всего комплекса сложившегося к настоящему периоду антинаучного консорциума.

Определившись с сущностным пониманием паранауки, мы сконцентрируемся на философско-методологическом понимании паранаучной субкультуры, исследовав ее в качестве подсистемного целостного и относительно изолированного формообразования, сопровождающего всю историю европейского рационализма (науки), генезис которого укоренен в «предыстории» ранних форм духовно-практического опыта человечества. Среди многообразия духовных нетрадиционных форм, изначально отличающихся своей «субкультурностью», инаковостью, в известном смысле нетрадиционностью, паранаука обнаруживает свою специфику прежде всего на границах науки, тем самым какбы «оправдывая» закрепившуся за ней дефиницию «пара».

В исследовании субкультурности паранауки (шире - ее субкультурной феноменологии) мы придерживаемся направления, в котором работают представители философско-антропологической и культурно- антропологической методологии познания, опираясь на философско-методологическое, во многом инновационное, понимание и трактовку культуры, разработанное отечественными авторами. Исходя из этого, культура трактуется нами как «идеальные формы деятельности, приобретающей общезначимое (универсальное) значение в конкретном культурно-историческом времени и социокультурном пространстве, что предполагает учет хронотопных характеристик деятельного индивида, конкретного человека, включенного в специфические сообщества и группы, в которых и реализуются, собственно, все коммуникативные акты, формируются специфические концепты и дискурсы, выраженные не только и не столько в естественном языке, сколько в языках «вторичных» знаково-символических формах и системах - от мифологических до интернетдискурса» [8, с. 71]. Такое понимание сущности культуры и предложенный подход к ее исследованию является «синтетическим», комплексным и мультидисциплинарным, во многом перекликаясь с работами отечественных исследователей и с положениями западной культурной антропологии.

При этом правомерно исходить из того, что «не существует какого-то особого, субстанциального «мифологического», «религиозного» 
или же «научного» сознания и самосознания, а есть лишь их конкретно-исторические формы, которые проявляются и закрепляются в специфических формах деятельности, в том числе и духовной, мыслительной, в продуктах этой деятельности, выраженных в знаково-символических системах как носителях специфических культурных кодов» [9, с. 67]. Выступая целостной системой с присущей ей внутренней определенностью ценностноиерархических взаимоотношений культура включает в себя (наряду с ценностной доминантой-ядром) множество самых разных подсистемных субкультурных образований. В данном методологическом ключе, мы и подходим к пониманию феномена паранаучной субкультуры.

Следует сказать, что нередко на границах паранауки обнаруживает себя так называемая «околонаучная мифология» (в частности, материалистический миф, иррациональные проявления которого можно обнаружить задолго до возникновения самой науки). Например, изображение людей на полотнах художника XVI в. Брейгеля Старшего в виде безликой массы, подчиненной великим законам, управляющим земными событиями по образцу управления орбитами во Вселенной. Ее содержанием является один великий механизм, а вся человеческая жизнь протекает по предначертанной траектории. Интерпретация такого понимания мира зарождалась в бессознательных глубинах европейского общества, опережая на столетие работы Ньютона, законы которого можно было бы использовать в виде основы для механистического понимания мироустроения. Так, например, в художественной форме находили свое выражение архетипические структуры коллективного бессознательного, рождающегося «нового времени», модерна. Свое завершение научная мифология и получила в эпоху Просвещения. Как верно подчеркивает В.П. Римский, «... новая эпоха использовала теперь не столько мифологические образы и символы в чистом виде, сколько их превращенные, $p a-$ циионально-понятийные, псевдонаучные формы; ... мифы науки и мифы о науке достраивают первоначально субкультурную форму научного познания и творчества до «общезначимости», дминирования и публичности в культурно-идеологическом дискурсе (духе) эпохи» [10, с. 67].

Паранаучные духовные формы будучи «другими» по отношению к базовой куль- туре и выделяющиеся своей «субкультурностью», практически всегда занимали (и частично находятся сегодня) на особом, «осадном субкультурном положении». В этом плане за ними в сравнении, скажем, с «материнской» культурой, центрирующей всю иерархию господствующих ценностных ориентаций, прочно закрепился статус «вторичных» периферийных и маргинальных феноменов» [11, с. 4].

Однако, как уже говорилось, роль подсистемных субкультурных формообразований отнюдь не однозначна: на общем фоне социального мифотворчества такая позитивная миссия субкультурных феноменов, спроецированных на конкретного «живого индивида» продолжает сохранять свою привлекательность.

В ряде работ мы уже указывали на определенные трудности в области категориального анализа дефиниции «паранаука» [12, с. 28-39; 13, с. 254-26о], в которых говорили, что, как правило, паранаука рассматривается как маргинальная девиация в целостной системе знания, что, несмотря на внешнюю консолидацию паранаучного движения, его формы, представленные классификацией паразнания, крайне разнообразны. А структуры современных паранаучных коммуникаций, иллюстрирующие мозаичность паранаучной субкультуры в диапазоне от лже, квази до антинауки, отличаются жесткостью и нетекучестью границ, стабильным и надежным характером соединений, обязательностью всецело придерживаться образцов. Они скорее противоречивы, нежели постоянны, отличаются миксовой природой, прозрачными границами, текучестью и временными солидарностями [14] .

Заметим, что в феноменологии современной культуры паранаучный ренессанс подпитывается кризисными процессами в классической научной методологии, резонирующими разрушением самих оснований методологической критики паранаучного комплекса. К тому же «при всем своем корпоративном солидаризме, радикализме и даже нетерпимости модель традиционной научной критики, на которую ранее ориентировалось научное сообщество в качестве доминирующей культуры модерна, дает очевидные сбои. Разумеется, это ускоряет процессы регенерации «двойников» науки, территория которой засоряется различного рода симулякрами, дрейфующими на ее границах, поглощаясь парадискурса- 
ми с размытой рациональной составляющей» $[15$, c. 21].

Таким образом, по сути, исследование культурно-исторической феноменологии паранауки во многом определяется инновационностью понимания самой культуры, «синтетическим», комплексным и мультидисциплинарным подходом к ее трактовке с учетом хронотопных характеристик деятельного индивида, конкретного человека, включенного в специфические субкультурные сообщества и группы. При таком подходе современная паранаука представляет собой подсистемный маргинальный комплекс, способствующий формированию специфической внутринауч- ной структуры, несвоевременная элиминация которого создает неадекватные образы науки.

Одновременно считаем важным подчеркнуть: для оценки паранаучных построений такого критерия как прямое сравнение с научными дискурсами недостаточно. На наш взгляд, здесь крайне необходим методологический, культурологический и социально-психологический анализ более широкого целого - способов освоения действительности и реализации личности в европейской культуре. Все это говорит о том, что исследование культурно-исторической феноменологии паранауки актуально и для самой науки, и для философии, и для культуры.

\section{Библиография:}

1. Кохановский В.П., Пржиленский В.И., Сергодеева Е.А. Философия науки. Ростов Н/Д, 2006.

2. Иванов К. П. Агрессивная лженаука // Вестник РАН. 2002. Т. 72. № 1. С. 30-36.

3. Щавелев С.П. Этика и психология науки. Дополнительные главы курса истории и философии науки. Курск, 2010.

4. Уколова В.И. Под сенью королевской арки // Морамарко М. Масонство в прошлом и настоящем: Пер. с ит./ Вступ. ст. и общ. ред. В. И. Уколовой. М., 1989. С.

5. Калинина Г.Н. Дисс ... д.филос. н. / 09.00.01 - теория и история культуры. Белгород: НИУ «БелГУ», 2015. $286 \mathrm{c}$.

6. Розин В.М. Демаркация науки и религии. Анализ учения Эммануэля Сведенборга. М., 2007.

7. Розин В.М. Мышление и творчество. М., 2006; Типы и дискурсы научного мышления. М., 2000.

8. Римская О.Н., Римский В.П. Методология исследования субкультур в социально-гуманитарных науках. Статья 4. Конфигурации молодежных субкультур в пространстве российского региона // Научные ведомости БелГУ. Серия Философия. Социология. Право. №20 (91). Вып. 14. Белгород, 2010.

9. Римская О.Н., Римский В.П. Современное мифосознание и субкультурные религии // Научные ведомости БелГУ. Серия Философия. Социология. Право. №8 (127). Вып. 20. Белгород, 2012.

10. Игнатова В.С., Римский В.П. Генезис науки, инноваций и научного университета (к девяностолетию со дня рождения М.К. Петрова) // Наука. Искусство. Культура / Научный рецензируемый журнал БГИИК. Вып 2. Белгород, 2013.

11. Римский В, Римская О. Феномен субкультурных религий / Монография. Саарбрюкен, Palmarium Academic Publishing, 2012.

12. Калинина Г.Н., Римский В.П. Самополагание науки и превращенные формы знания // Научные ведомости БелГУ. Серия «Философия. Социология. Право». № 20 (139) 2012. Вып. 22. Белгород, 2012. С. 28-39.

13. Калинина Г.Н. Рациональная и паранаучная формы миропонимания // Научные ведомости БелГУ. Серия «Философия. Социология. Право». № 8 (127) 2012. Вып. 20. Белгород, 2012. С. 254-260.

14. Омельченко Е.Л. Про эмо, готов и нравственность // URL: http: //www.polit.ru/autor/2009/01/23/subkult. html.

15. Калинина Г.Н. Автореф. диссертации ... д.филос. н. / 09.00.01 - теория и история культуры. Белгород: НИУ «БелГУ», 2015. 45 с.

\section{References (transliterated):}

1. Kokhanovskii V.P., Przhilenskii V.I., Sergodeeva E.A. Filosofiya nauki. Rostov N/D, 2006.

2. Ivanov K. P. Agressivnaya lzhenauka // Vestnik RAN. 2002. T. 72. № 1. S. 30-36.

3. Shchavelev S.P. Etika i psikhologiya nauki. Dopolnitel'nye glavy kursa istorii i filosofii nauki. Kursk, 2010.

4. Ukolova V.I. Pod sen'yu korolevskoi arki // Moramarko M. Masonstvo v proshlom i nastoyashchem: Per. s it./ Vstup. st. i obshch. red. V. I. Ukolovoi. M., 1989. S. 


\section{Культура и искусство 4(34) • 2016}

5. Kalinina G.N. Diss ... d.filos. n. / 09.00.01 - teoriya i istoriya kul'tury. Belgorod: NIU «BelGU», 2015. 286 s.

6. Rozin V.M. Demarkatsiya nauki i religii. Analiz ucheniya Emmanuelya Svedenborga. M., 2007.

7. Rozin V.M. Myshlenie i tvorchestvo. M., 2006; Tipy i diskursy nauchnogo myshleniya. M., 2000.

8. Rimskaya O.N., Rimskii V.P. Metodologiya issledovaniya subkul'tur v sotsial'no-gumanitarnykh naukakh. Stat'ya 4. Konfiguratsii molodezhnykh subkul'tur v prostranstve rossiiskogo regiona // Nauchnye vedomosti BelGU. Seriya Filosofiya. Sotsiologiya. Pravo. №20 (91). Vyp. 14. Belgorod, 2010.

9. Rimskaya O.N., Rimskii V.P. Sovremennoe mifosoznanie i subkul'turnye religii // Nauchnye vedomosti BelGU. Seriya Filosofiya. Sotsiologiya. Pravo. №8 (127). Vyp. 20. Belgorod, 2012.

10. Ignatova V.S., Rimskii V.P. Genezis nauki, innovatsii i nauchnogo universiteta (k devyanostoletiyu so dnya rozhdeniya M.K. Petrova) // Nauka. Iskusstvo. Kul'tura / Nauchnyi retsenziruemyi zhurnal BGIIK. Vyp 2. Belgorod, 2013.

11. Rimskii V, Rimskaya O. Fenomen subkul'turnykh religii / Monografiya. Saarbryuken, Palmarium Academic Publishing, 2012.

12. Kalinina G.N., Rimskii V.P. Samopolaganie nauki i prevrashchennye formy znaniya // Nauchnye vedomosti BelGU. Seriya «Filosofiya. Sotsiologiya. Pravo». № 20 (139) 2012. Vyp. 22. Belgorod, 2012. S. 28-39.

13. Kalinina G.N. Ratsional'naya i paranauchnaya formy miroponimaniya // Nauchnye vedomosti BelGU. Seriya «Filosofiya. Sotsiologiya. Pravo». № 8 (127) 2012. Vyp. 20. Belgorod, 2012. S. 254-260.

14. Omel'chenko E.L. Pro emo, gotov i nravstvennost'// URL: http: //www.polit.ru/autor/2009/01/23/subkult. html.

15. Kalinina G.N. Avtoref. dissertatsii ... d.filos. n. / 09.00.01 - teoriya i istoriya kul'tury. Belgorod: NIU «BelGU», 2015. $45 \mathrm{~s}$. 